(c) American Dairy Science Association, 2006.

\title{
Major Advances in Applied Dairy Cattle Nutrition
}

\author{
M. L. Eastridge \\ Department of Animal Sciences, The Ohio State University, Columbus 43210
}

\begin{abstract}
Milk yield per cow continues to increase with a slower rate of increase in dry matter intake; thus, efficiency of ruminal fermentation and digestibility of the dietary components are key factors in improving the efficiency of feed use. Over the past $25 \mathrm{yr}$, at least 2,567 articles relating to ruminant or dairy nutrition have been published in the Journal of Dairy Science. These studies have provided important advancements in improving feed efficiency and animal health by improving quality of feeds, increasing feedstuff and overall diet digestibility, better defining interactions among feedstuffs in diets, identifying alternative feed ingredients, better defining nutrient requirements, and improving efficiency of ruminal fermentation. The publications are vital in continuing to make advancements in providing adequate nutrition to dairy cattle and for facilitating exchange of knowledge among scientists.

Forages have been studied more extensively than any other type of feed. Cereal grains continue to be the primary contributors of starch to diets, and thus are very important in meeting the energy needs of dairy cattle. Processing of cereal grains has improved their use. Feeding by-products contributes valuable nutrients to diets and allows feedstuffs to be used that would otherwise be handled as wastes in landfills. Many of these by-products provide a considerable amount of protein, nonforage fiber, fat, and minerals (sometimes a detriment as in the case of $\mathrm{P}$ ) to diets. The primary feeding system today is the total mixed ration, with still considerable use of the pasture system. Major improvements have occurred in the use of protein, carbohydrates, and fats in diets. Although advancements have been made in feeding practices to minimize the risk of metabolic diseases, the periparturient period continues to present some of the greatest challenges in animal health.

Computers are a must today for diet formulation and evaluation, but fewer software programs are developed by universities. Several nutrition conferences are held
\end{abstract}

Received September 21, 2004.

Accepted November 15, 2004.

E-mail: eastridge.1@osu.edu regularly in the United States that are vital for transferring knowledge to the feed industry and the producers of food; the attendance at such programs has increased about 4 -fold over the past 25 yr. More emphasis on animal welfare will direct some of the areas of nutrition research. Challenges ahead include having adequate funding for conducting applied nutrition research and for training of students as scientists and for employment in the feed industry.

Key words: feeds, feeding system, nutrient, technology transfer

\section{INTRODUCTION}

Since the 75th year dedication of the Journal of Dairy Science, at least 2,567 articles relating to ruminant or dairy nutrition have appeared in the journal. Most of these research studies have related to mature dairy animals, but many have focused on the growing heifer and a few studies were conducted with goats or sheep. During the last $25 \mathrm{yr}$, milk yield per cow has increased about $2 \%$ per year (Figure 1). With this increasing milk yield per animal, DMI has increased to supply the increased demand for nutrients. However, the rate of increase in energy requirement has increased more rapidly than DMI, thus leading to diets with higher nutrient density. The average increase in animal performance for the United States helps us visualize this change in nutrient density, but the top performing herds put this in more perspective. It is common for herds to average $12,500 \mathrm{~kg} / \mathrm{cow}$ of milk per lactation with cows that consume 25 to $27 \mathrm{~kg} / \mathrm{d}$ of DM. With the increases in performance per animal and limits to increases in DMI caused by rumen fill or satiety, diet density has continued to increase (e.g., from 1980 to $2003, \mathrm{NE}_{\mathrm{L}}$ density needed to support average milk production has increased from 1.23 to $1.36 \mathrm{Mcal} / \mathrm{kg}$ of dietary DM; $\geq 1.6 \mathrm{Mcal} / \mathrm{kg}$ is now typical for high-producing cows), and considerable focus in research has occurred on improving feed efficiency (increased from 0.91 to $1.20 \mathrm{~kg}$ of $4 \% \mathrm{FCM} / \mathrm{kg}$ of DMI; common goal $=1.5$ ) and animal health by improving quality of feeds, increasing feedstuff and overall diet digestibility, better defining interactions among feedstuffs in diets, identifying alternative feed ingredients, better defining nutrient re- 


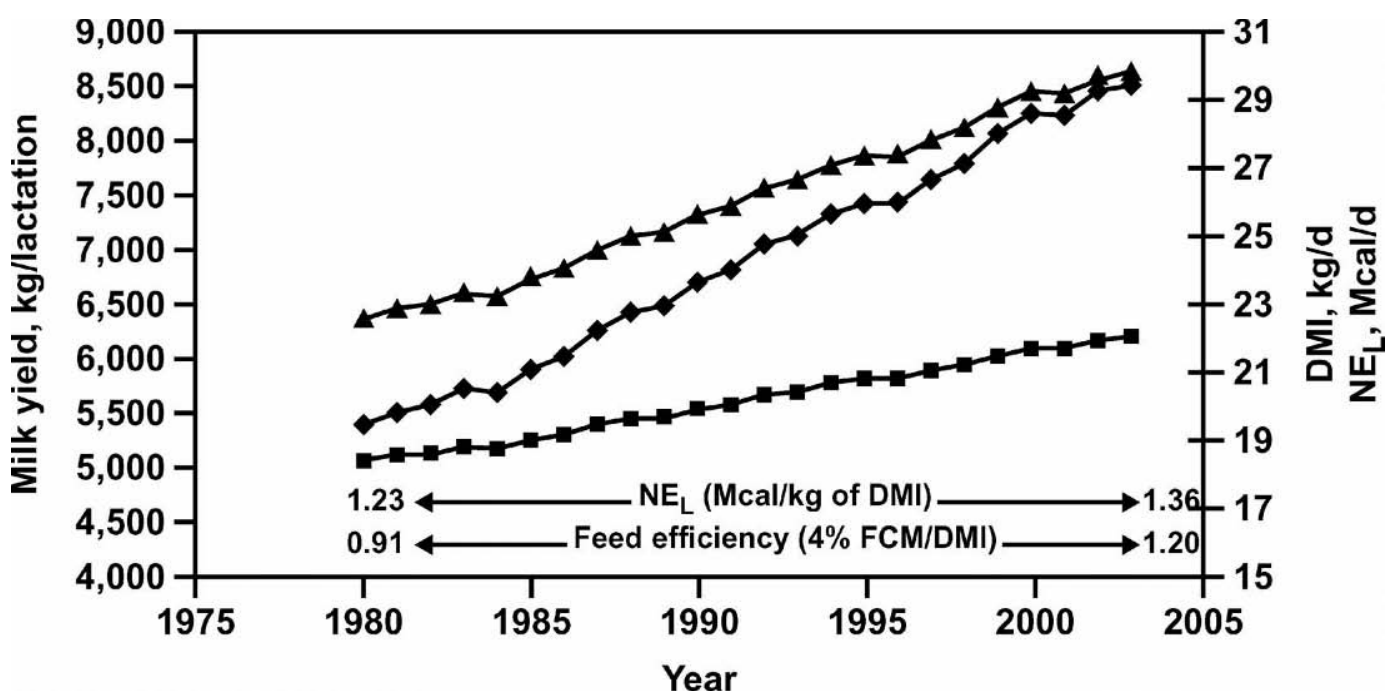

Figure 1. Changes from 1980 to 2003 in milk yield ( ), DM intake (

quirements, and improving efficiency of ruminal fermentation.

The NRC publications on the Nutrient Requirements of Dairy Cattle (e.g., NRC, 1989; 2001) have provided an excellent mechanism whereby the scientific community can integrate the data published in the Journal of Dairy Science and other peer-reviewed journals. The information in the NRC publications has been used extensively in teaching and research. Moreover, these publications have served as the handbook for dairy nutritionists in the field and for the basis of computer software development for formulation and evaluation of diets for dairy cattle. However, the new discoveries occur much more rapidly than do new editions of the NRC. Because of this and to increase the dialogue among the scientific community and personnel in feed companies, feed ingredient suppliers, and commercial laboratories, nutrition conferences and the corresponding proceedings published from the conferences have become very important vehicles in communicating new scientific data.

The manuscripts published in the Journal of Dairy Science are primarily for the purpose of communicating discoveries and for exchange within the scientific community. Educators and service providers to the dairy industry must be able to apply the scientific information to assist farmers in making feeding decisions and improving the profitability of the dairy enterprise and the health of the animals. The major advances in applied dairy cattle nutrition made during the past $25 \mathrm{yr}$ will be presented in this paper.

\section{FEEDS}

\section{Forages}

Forages remain a vital part of the diet for dairy cattle to maintain rumen health, and in many cases, for reduc- ing costs associated with feeding; therefore, more research has been reported with forages than with other types of feed (Figure 2). Forages under primary investigation include alfalfa, whole plant corn, whole plant sorghum, cereal grains, and grasses, including cool-season (orchardgrass, ryegrass, and fescue) and warm-season (bermuda) grasses. The inverse relationship between advancing maturity and forage quality was well established decades ago, resulting in few publications in this area during the last $25 \mathrm{yr}$. Research on storage of wet forages for silage has focused mostly on minimizing DM losses and proteolysis during harvest and storage. Minimizing losses during storage is primarily dependent on adequate DM at time of storage and optimizing anaerobic fermentation. The DM at the time of storage is affected mostly by stage of maturity at harvest and weather conditions. Anaerobic fermentation is affected by the DM content, chemical composition of the forage, and exclusion of oxygen in the storage structure. Silage additives are used to accelerate the anaerobic fermentation. Organic acids (especially propionic acid) are commonly added at the time of ensiling to hay-crop forages or to grain-crop forages harvested in less than ideal conditions. Inoculation of silages (especially hay-crop silage) with lactic acid bacteria may improve fermentation characteristics of the silage, but animal and economic responses are variable. Cuttings of hay-crop silage (e.g., alfalfa) in the spring or late fall when cool temperatures exist have lower populations of indigenous organisms and may be better preserved with addition of inoculants. Inoculation of silages with Lactobacillus buchneri at the time of ensiling increases acetic acid in the fermented silage and improves aerobic stability in the feed bunk. Ammoniation of whole plant corn and alfalfa for silage may increase fiber digestibil- 


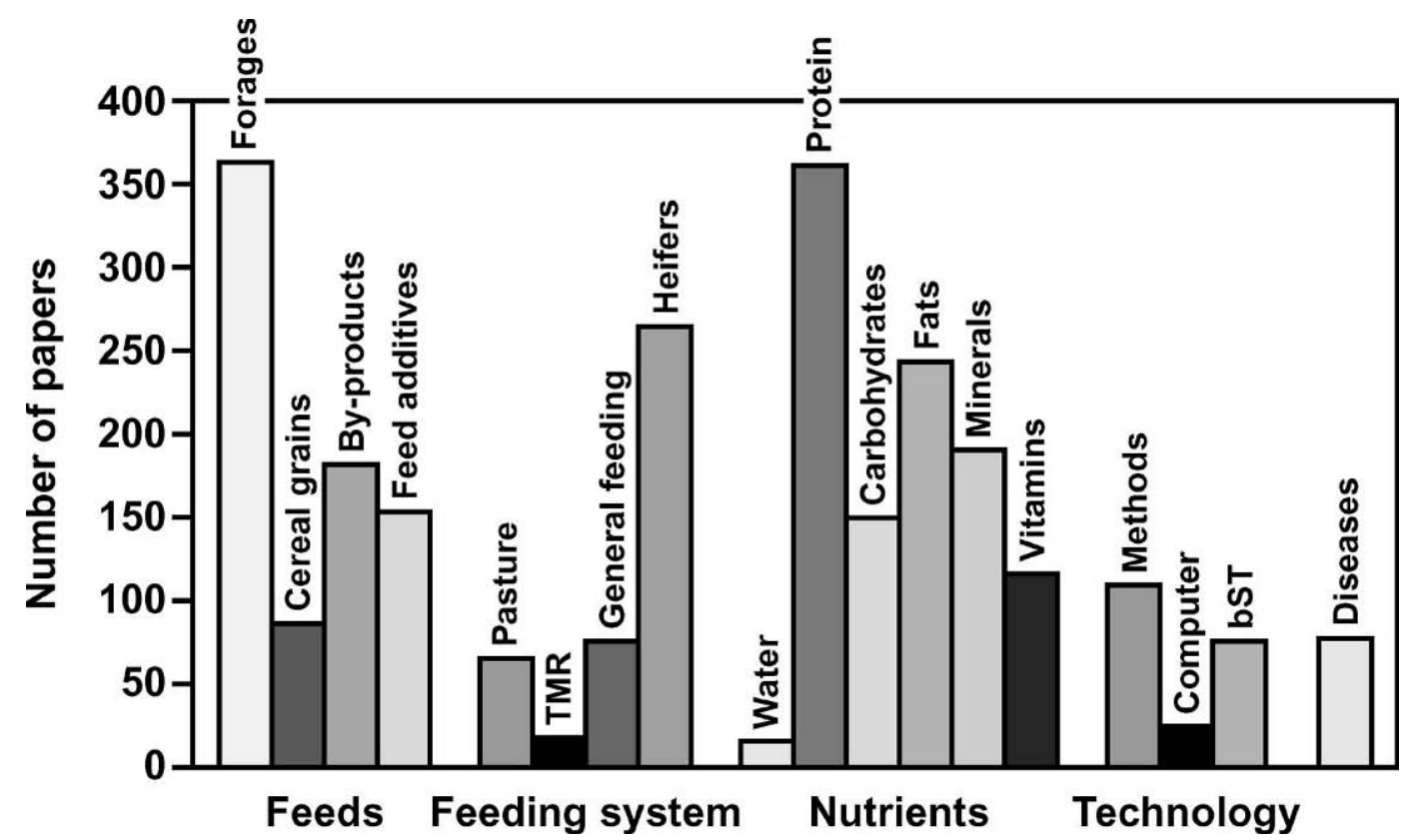

Figure 2. The relative distribution into topical categories of nutritionally related articles appearing in the Journal of Dairy Science from 1981 through 2004 . The distribution is relative because often an article related to more than one category, but was placed in only one category.

ity and aerobic stability. Addition of enzymes to forages at the time of ensiling has provided for inconsistent results.

Research has demonstrated that digestibility of low quality forages (e.g., straw) can be improved by ammoniation or alkali treatment. Although high-quality grass hay should not be ammoniated because toxins may form, addition of ammonia or urea to high-quality legume hay is sometimes practiced when the hay is high in moisture ( $>25 \%)$ to aid in forage preservation (minimize DM losses). Chemical drying agents for hay have reduced drying time to reduce harvest losses, but losses are increased if the treated hay gets wet. Chemical composition of forage and effects of particle size of forage on rumen health and chewing behavior have been extensively studied and will be discussed in detail later.

Besides addition of additives, research with corn silage has included chop height, whole plant processing, and different hybrids. Typically, chop height has been about $15 \mathrm{~cm}$, but increasing chop height up to $40 \mathrm{~cm}$ reduces NDF content, increases in vitro NDF digestibility, and thus increases energy concentration per unit of DM. However, DM yield is reduced and milk yield has not responded consistently to warrant widespread changes in harvesting practices. Using a roller (installed in the chopper after the cutting knives) on the whole plant corn was initially studied to increase digestibility of the corn kernel (too many whole kernels were being undigested), but research has shown that whole plant processing increases the digestibility of the kernel and stover portions, and with the decrease in equipment costs, this process has gained widespread acceptance. Processing has greater effects on digestibility when corn plants are beyond the one-half milk line stage of maturity. The focus on different hybrids has included high NDF digestibility, leafy, high-oil, waxy, and brown-midrib hybrids. Considerable variation has been demonstrated in NDF digestibility among different corn hybrids, and those with the highest NDF digestibility should be selected for feeding to dairy cattle. The waxy hybrids generally do not match the yield of the regular-dent varieties. The high-oil hybrids have only a marginal increase in whole plant oil concentration because the increase in oil concentration is in the grain only and yields in conjunction with agronomic factors have limited their acceptance for forage. Research with the brown-midrib corn (and sorghum) has consistently shown a decrease in lignin concentration in the forage and an increase in vitro NDF digestibility. However, selection of these hybrids is limited because animal performance has not consistently increased in the studies, agronomic costs are higher, and there are problems with lodging if harvest is delayed.

\section{Cereal Grains}

Most of the research with cereal grains has been with corn, barley, sorghum, and wheat, and has been re- 
cently reviewed (Theurer et al., 1999; Firkins et al., 2001). Reducing particle size of cereal grains by mechanical processing (grinding or dry rolling) increases ruminal starch digestibility but may slightly reduce ruminal NDF digestibility, and the benefit of the processing is greater for the starch sources with lower ruminal digestibility of starch (e.g., sorghum > corn $>$ barley $>$ wheat). Steam flaking of cereal grains causes gelatinization of the starch, which results in increased ruminal and total-tract digestibilities of starch (higher digestibility with low vs. high flake density; e.g., 0.26 vs. $0.39 \mathrm{~kg} / \mathrm{L}$ ), with the most pronounced results for sorghum. Ruminal starch digestibility is generally increased with the following processes (from highest to lowest): steam flaking, steam rolling, roasting/dry rolling, dry rolling, and grinding. With increased ruminal digestibility, greater risks occur for causing low ruminal $\mathrm{pH}$. Ruminal digestibility of starch must be considered in diet formulation along with NDF fractions, particle size of fiber sources, and use of ruminal buffers for maintaining rumen health. Although diets generally have about 40 to $60 \%$ concentrates for lactating dairy cows in early and midlactation and 30 to $40 \%$ concentrates during late lactation, research has demonstrated that formulation of diets for a targeted forage-to-concentrate ratio is not adequate. The forage-to-concentrate ratio does not take into consideration the quality of the forage, particle size of the forage, the type and processing of the cereal grains, and the concentration of nonforage fiber sources in the diet to affect dietary starch concentration.

Addition of organic acids (especially propionic acid) and ammonia at the time of ensiling high-moisture grains may decrease mold growth and DM losses, especially in grains with $>75 \%$ DM. Reducing particle size of these grains prior to ensiling is important in accelerating anaerobic fermentation and improving feed stability during storage. Addition of ammonia and inoculating with Lactobacillus buchneri at the time of ensiling may increase aerobic stability of these highmoisture grains at the time of feeding, especially during months of elevated environmental temperatures.

\section{By-Products}

Dairy cattle and other food-producing animals allow for the use of by-product ingredients that would otherwise have to be as handled as wastes for landfills. Research with by-products has increased our knowledge of their chemical composition (including energy), effects of storage (especially for wet feeds) and processing (heating, pelleting, and particle size), and their effects on ruminal fermentation, animal performance, and milk composition. The economics of using specific by- products can be regional, as well as seasonal, based on harvest schedule of the primary commodity. Within the last $15 \mathrm{yr}, 3$ national symposia have been held on alternative (by-product) feeds, with proceedings published from each symposium (National Alternative Feeds Symposium, 1991, 1995, and 2003).

Widely used cereal grain by-products include wet and dry corn gluten feed, corn gluten meal, wet and dry brewers grains, distillers grains (with and without solubles; corn, barley, and sorghum sources), wheat middlings, and oat hulls. Almost all of the dry corn gluten feed produced in the United States was exported until recent years. With some changes in the world trade of commodities, more of this feedstuff is fed domestically than several years ago. With the emergence of biofuel production in the United States, the supply of distillers grains is going to rapidly increase and the ability of distilleries to find outlets for this by-product may limit the growth of the biofuel industry. Therefore, the economics of this feed is likely to be quite positive in the future.

Oilseed by-products include the meals (high in protein) after extraction of the oil, hulls, and whole cottonseed as a by-product from the ginning industry. Soybean meal is hardly regarded as a by-product because it is the most common protein supplement used in the United States; however, other oilseed meals such as cottonseed, canola, sunflower, and safflower are used in the areas where the seed is principally grown. In the drying of by-products, such as with distillers grains, the heat can decrease rumen degradability of the protein, but excessive heat can cause the Maillard reaction to render the protein indigestible. The availability of the protein from many heat-processed by-products has been studied. Soybean hulls are effective as a nonforage fiber source in diluting starch from rations of highproducing dairy cows, and cottonseed hulls are an effective source of fiber for optimizing ruminal fermentation. The hulls and cotton lint on whole cottonseed result in it being an effective fiber source, with it effectiveness being similar to forages, unlike the fiber from most other by-product feeds. Effects of gossypol, a toxic pigment in cottonseed, on cows and heifers is often minimized by limiting the amount of cotton products in diets, but cotton products are usually excluded in diets for bulls because of the negative effect of gossypol on viability of sperm.

Animal by-products studied include feather meal, meat and bone meal, blood meal, poultry meal, and tallow. Because of the low protein quality, feather meal is not widely used. With an effort to reduce the risk of bovine spongiform encephalopathy (BSE) in the United States, the Food and Drug Administration (FDA) enacted, in 1997, the restriction of feeding ruminant meat 
and bone meal to ruminants. Consequently, the feed industry began to separate ruminant and nonruminant meat and bone meal for feeding the nonruminant meat and bone meal to ruminant animals. Continual review of the risks of BSE by FDA may result in additional restrictions in the use of animal by-products as feed sources. Marine by-products include fish, crab, and shrimp meal and are used as protein sources.

Molasses is produced from sugar beets, sugar cane, and citrus products. Some by-products generated from the food industry that are used as animal feed include beet pulp, citrus pulp, bakery wastes, vegetables, apple and tomato pomaces, nut fractions and hulls, and whey. Dried whey is a common ingredient in milk replacers for young animals; and to minimize the costs of drying, it is sometimes fed in liquid form to mature animals.

\section{Feed Additives}

Ruminal buffers (especially sodium bicarbonate and sodium sesquicarbonate), ionophores (monensin and lasalocid), and yeast culture have been researched more extensively in the last $25 \mathrm{yr}$ than other feed additives. Based on their efficacy and low cost, ruminal buffers are commonly used in diets for high-producing dairy cows. Ruminal buffers are especially important in diets that are low or marginal in effective fiber. Ionophores increase the efficiency of growth of dairy heifers. Monensin was approved in 2004 by FDA for lactating cows in the United States based on increasing milk production efficiency, but ionophores also hold promise for reducing the risk of ruminal acidosis and ketosis. Results with yeast culture have been variable; however, the relatively low costs of the products and their potential for improving ruminal fiber digestion have resulted in their widespread inclusion in diets for lactating cows. With the goal of increasing intake of certain feeds or mixed diets, various feed flavors have been studied with mixed results. Direct-fed microbials are likely more effective in situations whereby the indigenous organisms in the gastrointestinal tract have been compromised; for example, oral use of antibiotics, and for use in young animals. The organisms must be live, and thus, the manner in which the products are added to diets is often cumbersome. Addition of fibrolytic enzymes to diets for dairy cattle is still under investigation.

In the 1980s, several studies were conducted with the addition of C-4 and C-5 VFA to diets for dairy cattle. Early in vitro research revealed that the addition of these VFA showed potential increases in fiber digestibility, but in vivo results were inconsistent. The mixture of these VFA was available commercially for a while but disappeared from the market in the 1990s.

\section{FEEDING SYSTEMS}

\section{Pasture}

Interest in rotational, intensively managed grazing systems has increased in the United States and the goal is usually focused on milk yield per cow rather than milk yield per acre as in New Zealand. In the United States, intensive grazing usually results in less milk per cow but higher income over feed costs than for nongrazing systems. Much effort has been extended in determining pasture intake and chemical composition of different species and stages of maturity of forages used in the pasture system. Work has also been conducted on observing grazing behavior as influenced by quality and species of the forage being grazed and supplemental feeding practices. One of the primary challenges in a grazing system is maintaining adequate energy balance during early lactation, and thus, grain and limited amounts of corn silage are fed to increase energy intake. With higher supplementation of grain, pasture intake will decrease, but usually less grain is fed with pasture than with dry-lot feeding systems. Grain is usually supplemented based on milk yield (about $1 \mathrm{~kg} / 4 \mathrm{~kg}$ of $4 \% \mathrm{FCM}$ ) or at a constant rate per cow per day regardless of milk yield (e.g., $9 \mathrm{~kg} / \mathrm{d}$ ).

Ruminal protein degradability is high in fresh forages; thus, research has focused on different amounts and sources of RUP for grazing cows. With the lower $\mathrm{NDF}$ concentration and higher moisture content of fresh forage than harvested forage, the effects of different nonforage fiber sources and feed additives on rumen stability and site of nutrient digestion for grazing cows have been studied. With less mastication and lower NDF concentration for fresh forage than harvested forage (lower NDF because fresh forage is less mature), milk fat percentage is often lower for pasture-fed cows. However, cows on pasture typically have a higher concentration of conjugated linoleic acid (CLA) in the milk than cows fed TMR, but the mechanism for this is still not fully understood. The rapid fermentation and froth formation in the rumen during grazing of alfalfa predispose cows to the risk of gas being trapped in the rumen to cause bloat.

\section{Forage and Grain Fed Separately}

During the last $25 \mathrm{yr}$, the number of tie-stall barns has dramatically dropped and tie-stall barns have been replaced with free-stall barns as herd size has increased. Thus, the feeding of grain in the parlor has dramatically decreased, caused by changes in types of housing systems and the desire to provide for more efficient parlor operations and feeding management. Forages were fed outside the parlor in a bunk or manger 
for hay. Cows do not spend adequate time in the parlor to eat sufficient grain to support high levels of milk yield, and even if they did, that would be too much grain in a single eating bout to maintain optimum rumen $\mathrm{pH}$ (maximum suggested is about $3.5 \mathrm{~kg}$ per feeding). Feeding grain outside the parlor has progressively changed from: 1) feeding some additional grain on the bunk with the forages (especially for the highest producing cows in the herd), 2) to magnet-activated grain feeders whereby the cow with a magnet or an extended piece of chain on the collar or neck chain could make as many visits and eat as much per visit as desired (buffers were added to the grain mix to limit intake and assist in maintaining rumen $\mathrm{pH}), 3$ ) to transponderactivated grain feeders whereby a cow with the transponder had ad libitum access to the grain, and 4) to computer-controlled grain feeders. The complexity of the computer-controlled system varied from 1 to 4 grain batches that could be mixed in different proportions for each respective cow and different levels of sophistication in the computer system that controlled the feeder. The calibration of the delivery system and cow data entry were often overlooked in routine management. Most of these systems have been replaced with feeding all of the grain and forage outside the parlor as a TMR.

\section{Total Mixed Ration}

Ensiling forage and grain together and feeding a TMR as a cube have been investigated. With reduction in flexibility for changing the forage-to-concentrate ratio and still needing to mix in other concentrate ingredients in addition to the grain, forage is almost always ensiled alone. Feeding the TMR as a cube appeared to support milk yield but resulted in decreased milk fat percentage, likely caused by inadequate intake of effective fiber.

Most of the research with TMR has focused on grouping strategies, nutrient density, moisture content, and minimizing the sorting of ingredients. Because grouping strategies are sometimes based on factors that are indirect to nutrient requirements and based on individual management preferences, grouping strategies are usually unique for each farm and make it difficult to focus on specific energy and protein densities for different milk yields. Often, farmers have noted decreases in milk yield as cows were switched from one group to another. This was likely caused by cows being switched to lower nutrient densities too soon because of housing restraints and social disruption within groups. To reduce these social problems, it is common today to group first-lactation animals into a single group regardless of milk yield and stage of lactation, to minimize the number of times an animal is switched among groups, and to make group changes in the evening when animals are more docile. With increasing milk yield per cow, many farmers have kept the same number of groups, but reduced the differences in nutrient densities among the TMR; several groups may be fed the same TMR. Although this management strategy is more apt for herds with very high milk yields, associated feed costs, body condition of cows, and environmental impacts (especially $\mathrm{N}$ excretion) need to be closely assessed.

Cows are usually fed TMR with DM concentrations of 40 to $60 \%$. Lower DM intake may occur with diets containing less than $40 \%$ DM. The reduced intake is likely caused by the higher intake of organic acids and other fermentation products from ensiled feeds (e.g., silages and high moisture grains) and possibly by the overall moisture content from ensiled feeds and wet commodities resulting in more total feed needing to be consumed (DM intake is more highly affected by DM consumed per meal rather than number of meals; wet TMR may reduce DM intake per meal). The higher moisture TMR also are less stable during periods of elevated environmental temperature. The TMR with more than 60\% DM may result in lower DM intake (possibility due to palatability) and are more prone to sorting. Moisture concentration and particle size of the forage (large particles are more prone to sorting) are the primary factors that affect sorting potential. As newer TMR mixers have been designed to handle more hay, the potential for sorting has increased.

\section{General Feeding Practices}

Many studies have been conducted in recent years on the feeding of transition cows (cows from about 3 wk prepartum to $30 \mathrm{~d}$ postpartum). These studies have focused on DM intake, milk yield, nutrient densities, metabolic diseases, and use of feed additives. Several studies have focused on the importance of adequate hours of feed access, feeding frequency, and feeding behavior with TMR. More emphasis has been placed on monitoring feed efficiency (output per unit of input) and minimizing feed costs per unit of output. Effects of environment on nutrient requirements and feed quality on animal performance have been studied. With increased emphasis on environmental compatibility of food animal production to minimize impacts on water and air qualities, several studies have focused on farm nutrient balance, especially as it relates to $\mathrm{N}$ and $\mathrm{P}$ (discussed more later).

\section{Heifers}

The perception is that heifers often receive little attention, even by farmers and scientists; however, more 
than 250 studies with calves or heifers were published in the Journal of Dairy Science in the last $25 \mathrm{yr}$. The importance of the timing of the feeding, amount, and quality of colostrum is still well recognized as being paramount for calf health and growth. These factors are more important than whether the colostrum is suckled from a bottle or provided by tubing the calf. However, about $31 \%$ of the dairy calves in the United States still get their first colostrum by nursing the dam and $37 \%$ are not weaned until 8 wk of age (average age at weaning $=8.4 \mathrm{wk}$; NAHMS, 2002). Several colostrum replacements have been studied, and although improvements in the replacements have been made, natural colostrum of high quality still excels. Some high-quality colostrum should be frozen for instances when a cow has low-quality colostrum at parturition. Although the colostrum can be thawed in a microwave oven without major disruption of antibodies, thawing it in warm water is preferred.

Different amounts and sources of fat for milk replacers have been studied, with the most common source used being animal fat. Protein sources studied for milk replacers include milk, fish, blood, and soybean. Although some improvements have been made in soybean protein isolates that are better used than nonpurified soybean proteins, the most common protein source used is milk. Ad libitum intake of cold, acidified milk replacer has been shown to be acceptable in some situations, but its use is infrequent. Different practices in the use of milk replacers in the United States with dairy calves have been reported (Heinrichs et al., 1995).

Low environmental temperatures increase the energy requirement of calves, especially those housed outdoors. For this reason, additional milk replacer with at least $20 \%$ fat should be fed during such periods. Additional milk replacer (total of 15 to $20 \%$ of BW), with higher nutrient densities, is fed for an extended time in accelerated calf rearing programs. Calves in this program are weaned about 2 wk later than calves in the traditional program (feeding milk replacer at $10 \%$ of BW; calves are weaned when they are eating about $0.7 \mathrm{~kg} / \mathrm{d}$ of grain). The accelerated growth programs increase growth rate and feed costs, and data are still being gathered to determine if these costs are returned by heifers being in lactation sooner with increased milk yield.

Calf starters play a key role in rumen development. Several studies have investigated different fiber and nutrient (especially protein) sources and concentrations in calf starters. Calf growth and health with many different dietary regimens have been reported. Included in these studies are efforts to minimize stress on animals at weaning by the feeding program and grouping strategy. Abrupt dietary changes should be avoided, and calves should be housed in small groups (usually 10 calves or less) of similar age and BW. The amount and ratio of metabolizable protein and metabolizable energy for growth and effects on mammary development have been studied. Excessive weight gain in the pubertal heifer should be avoided.

\section{NUTRIENTS}

\section{Water}

The single most important nutrient is water, and water metabolism of dairy cattle has been reviewed (Murphy, 1992). Various factors that affect water intake have been identified, and efforts to predict water intake for dry and lactating cows have been made. Quality of the water is important for intake potential and animal health. Chilling water during high environmental temperatures may increase DM intake and milk yield, but it may be less preferred by the animals and the economics are uncertain.

\section{Protein}

Protein has been studied more than any other nutrient (Figure 2). Within the last $25 \mathrm{yr}$, we have changed from balancing rations for $\mathrm{CP}$ to balancing for RDP and RUP fractions. Also, the RDP fraction is even further defined for the amount that is most rapidly degraded (soluble protein; usually at 25 to $30 \%$ of CP). From the $1989 \mathrm{NRC}$ to the $2001 \mathrm{NRC}$, equations for protein requirements were altered and emphasis was shifted to balancing diets for MP.

Many studies have been conducted to investigate the effect of protein source and feeding regimen on site of protein digestion and $\mathrm{N}$ efficiency. Concentrations of protein to feed prepartum vs. during different stages of lactation has received considerable attention. Closeup dry cows (last 2 to 3 wk of gestation) should generally be fed diets with 14 to $15 \% \mathrm{CP}$, with response to balancing for RUP being minimal. Feeding urea postpartum with different protein sources of varying degradabilities was studied. Also, the synergism of the rumen degradability of the protein in conjunction with the starch has been studied for optimizing synthesis of microbial crude protein (MCP).

Considerable effort has been extended in measuring $\mathrm{N}$ fractions in different feedstuffs. Increased use of the in situ and in vitro measures by commercial laboratories has occurred in response to demands by the feed industry for such information. The processing of protein sources, especially soybean meal, with heat by roasting, extruding, and expelling, formaldehyde treatment, and treatment with lignosulfonate for increasing the RUP fraction has received much focus, and several products 
based on this research are now available from commercial companies.

Milk and blood urea nitrogen have been related to efficiency of $\mathrm{N}$ use. As excessive CP or RDP are consumed, MUN and BUN increase. Elevated MUN and BUN also have been negatively associated with fertility, possibly caused by elevated concentrations of ammonia and (or) urea in the uterus. The MUN is more commonly measured than BUN because of ease of sampling. Moreover, many DHIA laboratories will measure MUN in the same milk samples as those taken for measuring milk composition and somatic cells. A positive relationship has been found between MUN and urinary N excretion, so that monitoring MUN can help reduce excessive $\mathrm{N}$ in manure.

More information is now available on the amino acid needs of dairy cattle, especially methionine and lysine. Several studies have been done with rumen-protected methionine and lysine and methionine-hydroxy analog. Protein sources are selected to provide a complement of amino acids in diets, and rumen-protected methionine is sometimes supplemented when high-producing cows are fed diets with primarily leguminous protein sources.

\section{Carbohydrates}

Carbohydrates compose the highest proportion of diets and are important for meeting the energy needs of animals and maintaining rumen health. The concentrations of nonstructural and structural fractions of carbohydrates in feeds play a major role in the estimation of the energy value of feeds (NRC, 2001). Energy concentration in diets fed prepartum and postpartum as affected by carbohydrates have been studied.

Sugar concentration in feeds varies and these carbohydrates are rapidly fermented in the rumen. Sugar supplementation to diets for lactating cows has received limited attention (although often practiced in the field) and has resulted in mixed responses. Of the nonfibrous fraction, starches are the highest proportion in the diet and have been the most studied, but they have not always been determined by very direct methods. The nitrogen-free extract fraction from the proximate analysis has been replaced with the fractions referred to as nonfiber carbohydrates $(\mathrm{NFC}=100 \%$ of $\mathrm{DM}-\% \mathrm{NDF}$ -\% CP - \% ash - \% fat) and nonstructural carbohydrates (NSC; determined by enzymatic analysis). These latter 2 fractions do differ, especially for ensiled forages because of the concentration of organic acids. The NFC fraction is used most often because few commercial laboratories offer NSC analysis. Efforts to refine the NFC fraction have been made, especially in determining the $\mathrm{N}$ in the $\mathrm{NDF}$ fraction to provide for $\mathrm{NDF}_{\mathrm{N} \text {-free. }} \mathrm{By}-$ products high in NDF and CP often are most affected by this correction.

Most of the starch is fermented in the rumen and is important for synthesis of MCP and propionic acid, which is used as a precursor for glucose synthesis in the liver. The rate and extent of starch digestion in the rumen has been altered by processing of grain and using different grain sources. The vitreousness of starch from different corn varieties has also been studied. The starch concentration in diets must be based on effectiveness of the fiber in the diet and relative rate of starch fermentation. This relationship is expressed in the 2001 NRC, whereby as maximum NFC increases from 36 to $44 \%$, minimum forage NDF increases from 15 to $19 \%$. In achieving these target concentrations, the NDF from nonforage sources often becomes important in diluting starch from diets.

Fiber is important for maintaining rumen health, but high dietary concentrations can limit DM intake by increased rumen fill. Effectiveness of fiber for stimulating rumination from forage and nonforage sources has received considerable attention (Mertens, 1997). Indices of chewing per kilogram of DM and NDF and milk fat percentage from feeding different fiber sources have resulted in different measures of effective fiber. Except for cottonseed (fiber from hulls and lint), forages of adequate particle size excel in effective fiber compared with nonforage sources; therefore, forage NDF is often used as an indicator of effective fiber in diets. Total $\mathrm{NDF}$ (percentage of diet or $\mathrm{BW}$ ), forage $\mathrm{NDF}$, and $\mathrm{ADF}$ are used as benchmarks for balancing diets for adequate fiber. The total NDF alone can be misleading as a measure of effective fiber, depending on the amount of NDF contributed by nonforage sources. Adequate particle size of the forage is important in providing for adequate effective fiber. The particle size of forage has been studied by wet and dry sieving in laboratory settings, but the Penn State Particle Size Separator has received the most widespread adoption in the field (Kononoff et al., 2003). With a better understanding of the interactions of dietary starch and fiber and particle size of forage, it is now understood that diets without hay can be fed without adverse effects. Long-stem hay is a good source of effective fiber, but adequate fiber can be provided in diets with ensiled forages.

\section{Fats}

With increasing milk yield, fat supplementation has increased because its energy density is higher than for other nutrients. Because of its energy density and no contribution to heat increment, feeding fat is common during the summer months when DM intake will likely be depressed. However, excessive concentrations of un- 
saturated fat will interfere with fiber digestion in the rumen and high concentrations of total fat may decrease DM intake. Analysis of fatty acids (FA) by gas chromatography has almost totally replaced ether extraction, especially in research laboratories. Generally speaking, unsaturated FA should not exceed about $4 \%$ of the diet and total FA should not exceed $6 \%$ of the diet, although several factors can affect the concentration that can be tolerated in given situations.

Most of the FA in the diet are in the form of triglycerides, and after lipolysis in the rumen, most of the unsaturated FA are biohydrogenated by bacteria. However, the extent of biohydrogenation can be affected by rate of passage, rumen $\mathrm{pH}$, the chemical form of the FA source (including rumen protection by formaldehyde treatment), and particle size of the FA source. Although it is well understood that ruminal bacteria do not use FA for energy, it is now better realized through in vitro work and use of duodenal cannulated cattle that bacteria synthesize FA, which results in more FA flowing to the duodenum than consumed. Feeding fat decreases methane production in the rumen.

The natural sources of fat most studied were tallow, white grease, animal-vegetable blends, and oilseeds. The oilseeds or oil from oilseeds studied included soybeans (raw, extruded, and roasted), cottonseed, rapeseed (or canola), linseed, flaxseed, and sunflower (regular and high oleic). Effects of particle size of soybeans, cottonseed, and canola on digestibility of the oilseeds have been studied. The commercial fat with the most research is calcium salts of FA. These products are rumen inert and are less biohydrogenated than natural fats. Some of the products are less palatable than natural fats, and efforts have been extended to overcome this. The next most studied commercial fats are the hydrogenated fats. These fats are rather inert in the rumen but have lower digestibility. The digestibility of these fats is characterized by: FA > triglycerides, small particles (prills) > large prills; and digestibility decreases with advancing degree of saturation.

\section{Minerals}

Most of the research with minerals has focused on the requirements for different productive stages, availability of the minerals from different sources, and the interactions of different minerals. Phosphorus nutrition has received renewed interest because of its potential effects on the environment. Diets with $\mathrm{P}$ concentrations of 0.38 to $0.42 \%$ are adequate, even for high-producing cows (>12,000 kg/yr of milk). Diets with higher concentrations of $\mathrm{P}$ do not benefit animals and increase $\mathrm{P}$ excretion.
Much effort has been extended in studying the dietary cation-anion difference for close-up dry cows and lactating cows. A negative DCAD is suggested for cows in the last $3 \mathrm{wk}$ of gestation to reduce the incidence of hypocalcemia, and a positive DCAD is needed for lactating cows. The most commonly studied microminerals were Se and $\mathrm{Cu}$. Better understood now are maternal transfer of Se, Se availability from different sources, and optimum Se concentration in blood.

\section{Vitamins}

The requirements for fat-soluble vitamins have been reviewed (Weiss, 1998). The vitamin with the most research is vitamin $\mathrm{E}$. In addition to its requirement, its association with Se, adequate blood concentration, and relationship in prevention of mastitis have been studied. Considerable work has been done with vitamin D in relation to its effect on $\mathrm{Ca}$ metabolism and incidence of milk fever. The effects of supplemental $\beta$-carotene on reproduction have been mixed.

Several studies with niacin have been conducted with variable results on prevention of ketosis; however, given the low cost of niacin, it is often fed in the field at 6 to $12 \mathrm{~g} / \mathrm{d}$. Research with biotin supplementation at about $20 \mathrm{mg} / \mathrm{d}$ has revealed that it can improve hoof health, and in some instances, may increase milk yield. Although choline is not a typical vitamin, it has been the focus of recent research. Choline is degraded in the rumen, so rumen-protected sources are needed for animal responses, and commercial products are available. Supplemental choline may increase milk yield and improve the transport of lipids, thereby reducing the incidence of ketosis.

\section{ADVANCES IN AND TRANSFER OF TECHNOLOGY}

\section{Research Methods}

Studies have been conducted to improve the use of in situ and in vitro procedures for measuring protein and fiber digestibilities and with different markers for determining digestibility in vivo. Improvements have been made in equations for predicting energy content of feeds and for predicting DMI of dairy animals. The fundamental determination of DM content of feeds has continued to receive attention, especially with the advent of the microwave oven for use in the field. Systems of scoring body condition have been described using a scale of 1 (thin) to 5 (fat), with different scores recommended based on stage of lactation. Improvements have been made in the NDF procedure, especially for feeds high in starch or fat. The use of near infrared reflectance (NIR) has received considerable attention. The near infrared reflectance equipment has become common in 
analysis of forages for DM, CP, fiber fractions, energy estimation, and digestibility of different fractions, but mineral concentrations are generally not estimated accurately.

\section{Computer Technology}

Computer software programs for least-cost formulation and evaluation of diets for dairy cattle have continued to be developed with greater degrees of complexity and for ease of use. Several of these programs were once developed by universities for teaching and outreach education (Eastridge et al., 1998); however, reductions in personnel and limited resources have resulted in only a few academic institutions keeping the programs updated. Most of the computer programs used in the feed industry are now commercially developed programs, some of which integrate feed inventory with feed formulations. These companies once ran the computations on a central mainframe computer, but today, the feed company representative takes the ration software program to the farm on a laptop or handheld computer.

Computer-based nutritional models are commonly used by nutritionists. The Cornell Net Carbohydrate and Protein System (Fox et al., 1992) has undergone several revisions. The Cornell-Penn-Miner computer model (Cornell University, Ithaca, NY) is commonly used in the field, and the NRC (2001) computer model has been widely distributed. The difficulty with all of the noncommercial programs will be the need for regular maintenance and resources for major revisions.

\section{Bovine Somatotropin}

Early research with bST was with daily injections and then sustained-released products became available. The FDA approved the use of bST for lactating cows in November 1993, but it was not until February 1994 that commercial bST could be sold. Today, only one commercial product is available (a 14-d sustainedrelease product). Several studies have clearly demonstrated a positive response in milk yield, no change in milk composition, and a 3- to 4-wk lag in the increase in DMI with the use of bST. Diet formulation strategies are the same for cows given bST as for other highproducing cows. The response to bST will not continue unless diets are formulated to provide adequate concentrations of nutrients (especially adequate energy). Incidence of metabolic diseases and mastitis, reproductive performance, and effects of heat stress on animals are similar with usage of bST compared with other methods to increase milk yield. Early in the approval of bST, it was very important to report whether nutritional stud- ies were conducted with cows receiving bST, but today, most of the studies with lactating cows are conducted with cows administered bST, although this may not be described in the methodology.

\section{Human Resources}

Nutrition conferences (along with the corresponding proceedings) in the United States have become increasingly important in technology transfer (Table 1, Figure 3 ). The oldest program is the Cornell Nutrition Conference, which began in 1938. Several states have united to offer these programs and attendance has increased about 4-fold over the past $25 \mathrm{yr}$. As mentioned earlier, human and fiscal resources at universities have become more limited. As a result, not every state has an extension specialist or researcher for dairy nutrition. Discussions continue at integrating human resource capital among universities in the United States. These conferences have served as multiplier effects for transferring nutrition research to the feed industry, which will in turn pass it on to the clients they serve. With the changes in the dairy industry (fewer farms with larger herd size) and consolidations within the feed industry, attendance at these conferences may soon begin to drop, but should retain a similar level of impact by reaching the same or greater portion of the feed and dairy industries.

\section{FUTURE NEEDS}

Much advancement has been made in applied dairy nutrition over the past $25 \mathrm{yr}$. Over the next few years, efforts to improve digestibility of dietary components (thereby increasing feed efficiency), to optimize ruminal fermentation, to improve use of $\mathrm{N}$ and $\mathrm{P}$ for the animal's benefit and to reduce the risk of contaminating the environment, and to further understand the nutritional requirements of animals will become increasingly important. Computer-based models and software for diet formulation and evaluation will become increasingly sophisticated, but direct university involvement in software development will become limited or nonexistent. Nutritional research that relates to understanding animal behavior and minimizing health problems will be driven by efforts to provide more focus on animal welfare. Challenges ahead include having adequate funding for conducting applied nutrition research and in funding of graduate students to conduct the research and to be available for employment in the feed industry. Universities can not afford to simply conduct producttesting research, but rather they must be creative in the design of research projects and in partnering with industry, including dairy farmers, at finding fiscal re- 
Table 1. Attendance at nutrition conferences held in the United States

\begin{tabular}{|c|c|c|c|c|c|c|c|c|c|c|c|c|c|c|c|}
\hline \multirow[b]{2}{*}{ Conference } & \multirow[b]{2}{*}{$\begin{array}{l}\text { Year } \\
\text { started }\end{array}$} & \multicolumn{9}{|c|}{ Attendance } & \multicolumn{5}{|c|}{ Category, $\%$ of attendees } \\
\hline & & 1980 & 1985 & 1990 & 1995 & 2000 & 2001 & 2002 & 2003 & $2004^{1}$ & $\begin{array}{l}\text { Feed } \\
\text { industry }\end{array}$ & Consultant & Vet & University & Farmer \\
\hline Arizona Production ${ }^{2}$ & 2002 & - & - & - & - & - & - & 50 & 120 & 200 & 5 & 25 & 5 & 5 & 60 \\
\hline California Animal Nutr. ${ }^{3}$ & 1968 & $\mathrm{NA}^{5}$ & NA & 214 & 165 & 221 & 235 & 246 & 260 & 305 & 10 & 70 & 5 & 10 & 5 \\
\hline Cornell Nutr. ${ }^{3}$ & 1938 & 216 & 185 & 224 & 333 & 380 & 356 & 490 & 465 & NA & 78 & - & - & 16 & 6 \\
\hline Florida Ruminant Nutr. ${ }^{2}$ & 1989 & - & - & 110 & 110 & 110 & 110 & 110 & 110 & 110 & 65 & 10 & 3 & 15 & 7 \\
\hline 4-State Appl. Nutr. and Mgmt. ${ }^{4}$ & 1991 & - & - & - & 400 & $500^{6}$ & 525 & - & 425 & - & 50 & 20 & 20 & 10 & - \\
\hline Intermountain Nutr. ${ }^{2}$ & 1999 & - & - & - & - & 80 & 100 & 110 & 125 & 110 & NA & NA & NA & NA & NA \\
\hline Maryland Animal Nutr. ${ }^{3}$ & 1953 & NA & NA & NA & NA & NA & NA & 125 & 191 & 210 & NA & NA & NA & NA & NA \\
\hline Mid-South Ruminant Nutr. ${ }^{2}$ & 1994 & - & - & - & 147 & 108 & 105 & 93 & 109 & 113 & 50 & 25 & 10 & 10 & 5 \\
\hline Minnesota Nutr. $^{3}$ & 1940 & 400 & 400 & 300 & 290 & 268 & 188 & 234 & 231 & NA & 74 & 5 & 5 & 15 & 1 \\
\hline New England Dairy Nutr. ${ }^{4}$ & 1959 & 100 & 100 & 80 & 80 & 150 & 150 & 150 & 150 & 150 & NA & NA & NA & NA & NA \\
\hline Pacific Northwest Animal Nutr. ${ }^{3}$ & 1965 & 150 & 150 & 150 & 135 & 120 & 115 & 150 & 110 & NA & 50 & 10 & 5 & 10 & 25 \\
\hline Penn State Dairy Cattle Nutr. ${ }^{4}$ & 2000 & - & - & - & - & 185 & 248 & 325 & 445 & NA & 65 & 15 & 15 & 5 & - \\
\hline Southwest Nutr. and Mgmt. ${ }^{2}$ & 1986 & - & 185 & NA & NA & NA & 230 & 204 & 212 & 236 & 60 & 20 & 10 & 10 & - \\
\hline Tri-State Dairy Nutr. ${ }^{4}$ & 1992 & - & - & - & 337 & 399 & 464 & 535 & 513 & 493 & 58 & 7 & 8 & 21 & 6 \\
\hline Total & & 866 & 1,020 & 1,078 & 1,997 & 2,519 & 2826 & 2822 & 3466 & NA & & & & & \\
\hline
\end{tabular}

${ }^{1}$ Not all conferences had been held in 2004 when the data were gathered.

${ }^{2}$ Ruminant species only.

${ }^{3}$ Ruminant and nonruminant species.

${ }^{4}$ Dairy cattle only.

${ }^{5} \mathrm{NA}=$ Not available.

${ }^{6}$ Held in 1999. 

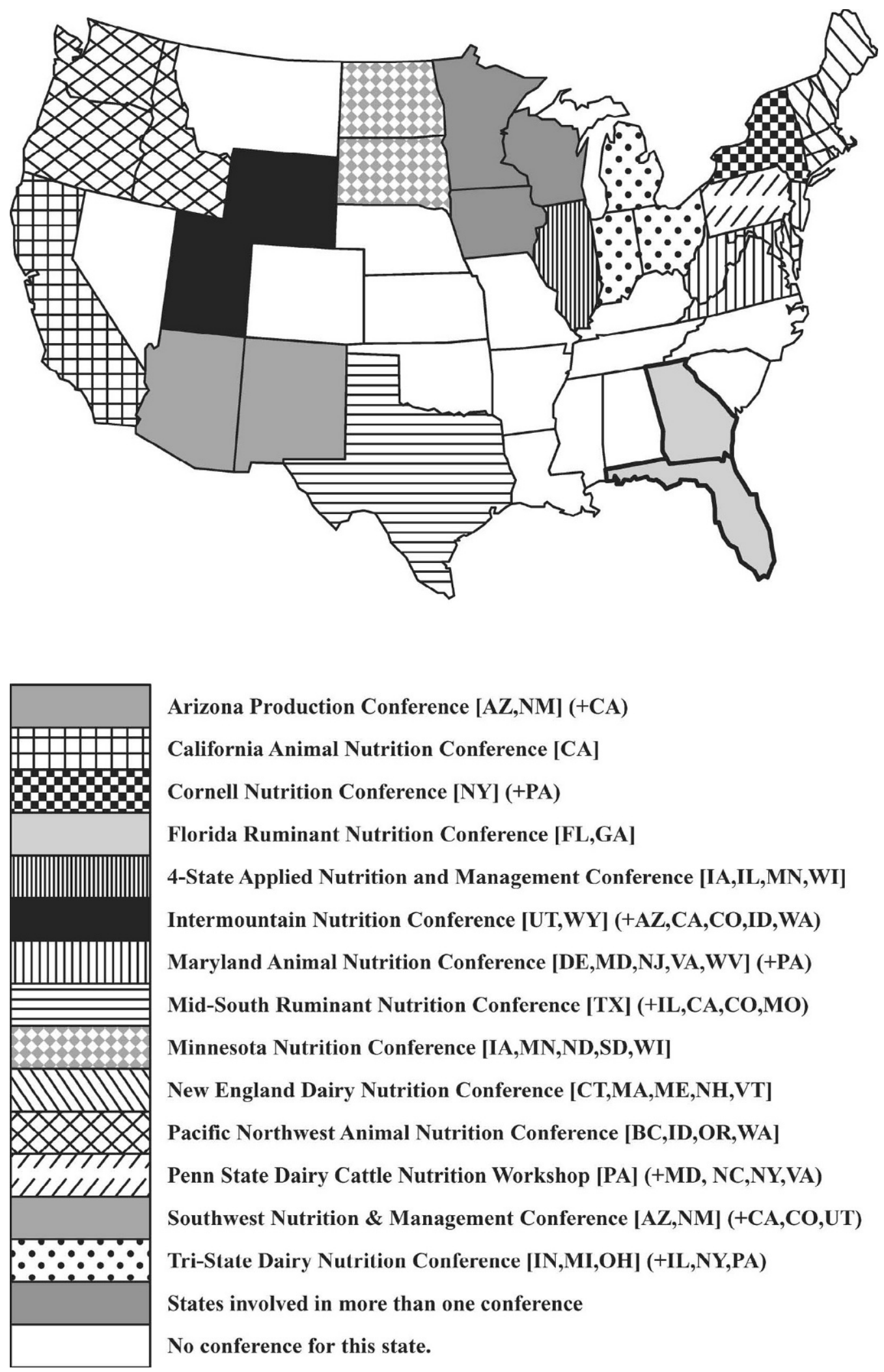

Arizona Production Conference [AZ,NM] (+CA)

California Animal Nutrition Conference [CA]

Cornell Nutrition Conference [NY] (+PA)

Florida Ruminant Nutrition Conference [FL,GA]

4-State Applied Nutrition and Management Conference [IA,IL,MN,WI]

Intermountain Nutrition Conference [UT,WY] (+AZ,CA,CO,ID,WA)

Maryland Animal Nutrition Conference [DE,MD,NJ,VA,WV] (+PA)

Mid-South Ruminant Nutrition Conference [TX] (+IL,CA,CO,MO)

Minnesota Nutrition Conference [IA,MN,ND,SD,WI]

New England Dairy Nutrition Conference [CT,MA,ME,NH,VT]

Pacific Northwest Animal Nutrition Conference [BC,ID,OR,WA]

Penn State Dairy Cattle Nutrition Workshop [PA] (+MD, NC,NY,VA)

Southwest Nutrition \& Management Conference [AZ,NM] (+CA,CO,UT)

Tri-State Dairy Nutrition Conference [IN,MI,OH] (+IL,NY,PA)

States involved in more than one conference

No conference for this state.

Figure 3. Map of the United States depicting states represented by conferences that relate to food animal nutrition. Primary states represented by the conference are shaded on the map. The legend shows the primary states in brackets, followed by the additional states (from which attendees travel) in parentheses. 
sources for conducting applied nutrition research and training of students for employment in the feed industry.

\section{REFERENCES}

Eastridge, M. L., H. F. Bucholtz, A. L. Slater, and C. S. Hall. 1998. Nutrient requirements for dairy cattle of the National Research Council versus some commonly used ration software. J. Dairy Sci. 81:3049-3062.

Firkins, J. L., M. L. Eastridge, N. R. St-Pierre, and S. M. Noftsger. 2001. Effects of grain variability and processing on starch utilization by lactating dairy cattle. J. Anim. Sci. 79(E. Suppl.):E218E238.

Fox, D. G., C. J. Sniffen, J. D. O’Conner, J. B. Russell, and P. J. Van Soest. 1992. A net carbohydrate and protein system for evaluating cattle diets: III. Cattle requirements and diet adequacy. J. Anim. Sci. 70:3578-3586.

Heinrichs, A. J., S. J. Wells, and W. C. Losinger. 1995. A study of the use of milk replacers for dairy calves in the United States. J. Dairy Sci. 78:2831-2837.

Kononoff, P. J., A. J. Heinrichs, and D. R. Buckmaster. 2003. Modification of the Penn State Forage and Total Mixed Ration Particle Separator and the effects of moisture content on its measurements. J. Dairy Sci. 86:1858-1863.
Mertens, D. R. 1997. Creating a system for meeting the fiber requirements of dairy cows. J. Dairy Sci. 80:1463-1481.

Murphy, M. R. 1992. Water metabolism of dairy cattle. J. Dairy Sci. 75:326-333.

National Alternative Feeds Symposium. 1991. Alternative Feeds for Dairy and Beef Cattle. E. R. Jordan, ed. St. Louis, MO. University of Missouri-Columbia.

National Alternative Feeds Symposium. 1995. Alternative Feeds for Dairy and Beef Cattle. M. L. Eastridge, ed. St. Louis, MO. University of Missouri-Columbia.

National Alternative Feeds Symposium. 2003. Alternative Feeds for Livestock and Poultry. M. L. Eastridge, ed. Kansas City, MO. The Ohio State University, Columbus.

National Animal Health Monitoring System. 2002. Part I: Reference of dairy health and management in the United States. National Center for Animal Health Surveillance, Ft. Collins, CO. Online. Available at: http://www.aphis.usda.gov/vs/ceah/cnahs/nahms/ dairy/dairy.htm

National Research Council. 1989. Nutrient Requirements of Dairy Cattle. 6th rev. ed. Natl. Acad. Sci., Washington, DC.

National Research Council. 2001. Nutrient Requirements of Dairy Cattle. 7th rev. ed. Natl. Acad. Sci., Washington, DC.

Theurer, C. B., J. T. Huber, A. Delgado-Elorduy, and R. Wanderley. 1999. Invited review: Summary of steam-flaking corn or sorghum grain for lactating dairy cows. J. Dairy Sci. 82:1950-1959.

Weiss, W. P. 1998. Requirements for fat-soluble vitamins for dairy cows: A review. J. Dairy Sci. 81:2493-2501. 